\title{
Escolha pela docência: estudo com egressos de uma Licenciatura em Matemática do interior do Ceará
}

Resumo: O ensino da Matemática passa por transformações significativas quanto à formação docente, mesmo que ainda não suficientes para suprir a carência de professores habilitados para essa função, sendo a atual LDB um marco para mudanças nesse cenário, ao exigir formação a nível superior para a docência. A partir das demandas dessa lei, em 2002 foi implantado o curso de Licenciatura em Matemática da Faculdade de Educação, Ciências e Letras do Sertão Central da Universidade Estadual do Ceará (FECLESC/UECE), a fim de reduzir a carência de docentes nessa região do interior do Ceará, tendo o referido curso mais de 15 anos de atuação e formado 91 professores. Nesse contexto, discutindo a docência e elementos relacionados à sua escolha enquanto profissão, esta pesquisa, configurada como um estudo de caso qualitativo, objetivou investigar se os egressos desse curso estão, de fato, atuando como docentes e, mais especialmente, o que os levou a optar ou não pela docência. Por meio da aplicação de um questionário junto a 50 ex-alunos do curso, obtivemos que 29 estão atuando na docência e 7 em cargos de gestão escolar; dentre os que não exercem a profissão, 14 não optaram pela carreira e apenas 1 está desempregado. Para nossos sujeitos, o ingresso na profissão docente foi pautado, principalmente, no gosto pela profissão. A pesquisa contribuiu para sabermos quais aspectos estão relacionados à escolha pela docência, permitindo refletir sobre a inserção no magistério e os desafios da educação.

Palavras-chave: Escolha pela Docência. Docência em Matemática. Licenciados em Matemática.

\section{Choice for teaching: study with graduates of a bachelor's degree in Mathematics in the interior of Ceará}

Abstract: The teaching of mathematics undergoes significant transformations in terms of teacher training, even if they are not yet sufficient to supply the lack of qualified teachers for this function, being the current LDB a milestone for changes in this scenario, by requiring training at a higher level for teaching. Based on the demands of this law, in 2002 the Mathematics degree course at the Faculdade de Educação, Ciências e Letras do Sertão Central of the Universidade Estadual do Ceará (FECLESC/UECE) was implemented, in order to reduce the lack of teachers in this region of the interior of Ceará, having that course over 15 years of experience and trained 91 teachers. In this context, discussing teaching and elements related to his choice as a profession, this research, configured as a 
qualitative case study, aimed to investigate whether the graduates of this course are, in fact, acting as teachers and, more especially, what led them to choose teaching or not. Through the application of a questionnaire to 50 alumni of the course, we obtained that 29 are working in teaching and 7 in school management positions; among those who do not practice the profession, 14 did not choose a career and only 1 is unemployed. For our subjects, entering the teaching profession was based mainly on the taste for the profession. The research contributed to know which aspects are related to the choice of teaching, allowing to reflect on the insertion in the teaching profession and the challenges of education.

Keywords: Choice for Teaching. Teaching in Mathematics. Graduates in Mathematics.

\section{La elección de la enseñanza: estudio con graduados de una Licenciatura en Matemáticas en el interior de Ceará}

Resumen: La enseñanza de las Matemáticas sufre transformaciones significativas en cuanto a la formación del profesorado, aunque aún no sean suficientes para suplir la escasez de docentes cualificados para esta función, siendo el actual LDB un hito de cambios en este escenario, al exigir formación a un nivel superior para enseñar. Con base en las exigencias de esta ley, en 2002 se implementó la carrera de Matemáticas en la Faculdade de Educação, Ciências e Letras do Sertão Central de la Universidade Estadual do Ceará (FECLESC/UECE), con el fin de reducir la escasez de docentes en esta región del interior del país. Ceará, habiendo dicho curso más de 15 años de experiencia y capacitado a 91 docentes. En este contexto, discutiendo la docencia y elementos relacionados con su elección como profesión, esta investigación, configurada como un estudio de caso cualitativo, tuvo como objetivo indagar si los egresados de esta asignatura están, de hecho, actuando como docentes y, más especialmente, lo que llevó que elijan enseñar o no. Aplicando un cuestionario a 50 egresados de la asignatura, obtuvimos que 29 se encuentran trabajando en la docencia y 7 en puestos directivos escolares; entre los que no ejercen la profesión, 14 no eligieron carrera y solo 1 está desempleado. Para nuestros sujetos, el ingreso a la profesión docente se basó principalmente en el gusto por la profesión. La investigación contribuyó a conocer qué aspectos están relacionados con la elección de la docencia, permitiendo reflexionar sobre la inserción en la profesión docente y los desafíos de la educación.

Palabra clave: Elección de la Enseñanza. Docencia en Matemáticas. Licenciados en Matemáticas.

\section{Introdução}

Diante das transformações no contexto educacional e das reformas curriculares ocorridas nos últimos anos, tem-se debatido cada vez mais sobre a formação dos professores e, de modo particular, do professor de Matemática. Mesmo com as mudanças no âmbito da cultura, formação docente e, sobretudo, políticas educacionais, antigos déficits ainda permeiam o cenário escolar, como, por exemplo, a carência de professores habilitados para o ensino dessa disciplina. 
Tal carência se mostra acentuada em escolas do interior, nas quais ainda se costuma encontrar professores com habilitação em áreas diferentes das quais atuam ou, ainda, não habilitados para a docência (GATTI e BARRETO, 2009). Tal cenário chama a atenção, especialmente de nós, pesquisadores, para que inicialmente se investigue a efetividade dos cursos de licenciatura, bem como sua distribuição e alcance, e, ainda, o encaminhamento dos licenciandos à profissão, pois somente a partir de estudos assim será possível projetar reajustes e novos horizontes para a docência, ensino e aprendizado de Matemática.

Essas questões mostraram-se concretas e latentes no contexto do Sertão Central cearense, de onde parte esta pesquisa, onde ainda é possível perceber descompassos entre a demanda de professores de Matemática e sua presença nas escolas. Tal panorama é composto, ainda, pelo curso de Licenciatura em Matemática da Faculdade de Educação, Ciências e Letras do Sertão Central (FECLESC), campus da Universidade Estadual do Ceará (UECE) na cidade de Quixadá / CE, referência na formação de professores dessa região do interior do estado, que atua há mais de quinze anos.

Partindo dessas discussões e, sobretudo, da presença atuante do referido curso de formação inicial em Matemática, percebeu-se a importância de pesquisar acerca dos egressos, a fim de identificar se esses assumiram ou não a docência como profissão e, sobretudo, quais motivos os levaram a fazer uma ou outra escolha. De modo indireto, buscamos nesta investigação entender por que a carência, verificada também em nossa experiência como docente, não foi sanada, após averiguarmos o campo de atuação profissional dos egressos do curso em questão.

Diante do exposto, a presente pesquisa tomou como base os seguintes questionamentos: Os licenciados em Matemática egressos do referido curso estão atuando como docentes? O que os levou a optarem ou não pela docência? De forma que, os objetivos deste trabalho consistem, pois, em investigar se esses sujeitos atuam como docentes e o que os motivou a escolher a docência ou não.

Esta pesquisa tem relevância científica, social e pedagógica, por contribuir no âmbito da formação docente em Matemática. A nível local, por permitir ao curso visualizar e perceber o panorama de licenciados até então entregues à sociedade e, assim, avaliar e aprimorar, se necessário, sua contribuição. Em esfera mais abrangente, permite, 
ainda, a reflexão acerca dos impactos da formação inicial que está sendo proporcionada aos nossos professores, de modo especial na constituição de suas identidades profissionais, escolha pela docência e atuação profissional.

O artigo está disposto da seguinte maneira: a seguir retomamos um pouco de nosso referencial teórico, a fim de contextualizar as categorias-chave da pesquisa. Mais à frente descrevemos nossas opções e percursos metodológicos. Após, apresentamos e discutimos os resultados, para, finalmente, trazermos nossas considerações de fecho.

\title{
2 A escolha pela docência: discutindo o cenário da profissão docente
}

As escolhas estão presentes em nossas vidas, umas simples, outras complexas, sendo uma delas a carreira profissional, que ganha importância sobremaneira no contexto da sociedade do trabalho. Essa escolha profissional é influenciada por vários fatores, dentre os quais destacam-se os afetivos, sociais, econômicos e políticos. Uma questão na conjuntura do trabalho da contemporaneidade, que vem causando insatisfações e desconfortos ao longo da vida do trabalhador, é que

a escolha da profissão geralmente ocorre em um momento em que as pessoas não têm maturidade e, tampouco, uma visão esclarecida acerca do que querem, ou mesmo para entenderem que um curso de graduação não é um movimento definitivo em suas vidas (SANTOS, TAVARES e FREITAS, 2013, p. 2).

A escolha da profissão ainda envolve, além desse, outros aspectos. Segundo Valle $(2006)^{1}$, citado por Santos, Tavares e Freitas $(2013$, p. 3) ela é influenciada no

\begin{abstract}
âmbito social, por todo o capital cultural que o aluno adquiriu ao longo de seu crescimento e formação; pela presença e relevância da família para o indivíduo, uma vez que esta irá delimitar as suas perspectivas de trabalho e de vida; e pela própria escola, que também participa dessa delimitação, fornecendo informações e abrindo conhecimentos referentes às diversas carreiras possíveis, além de esclarecer dúvidas e problemas que os alunos têm ao tomar sua decisão.
\end{abstract}

Há uma diversidade de questões que implicam essa decisão, sobretudo em se tratando da escolha pela docência como profissão a ser seguida, foco desta investigação, estando intimamente ligada à vida estudantil. Para Stamberg e Nehring (2016, p. 3), “os

\footnotetext{
${ }^{1}$ VALLE, Ione Ribeiro. Carreira do magistério: uma escolha profissional deliberada? Revista Brasileira de Estudos Pedagógicos, Brasília, v. 87, n. 216, p. 178-187, maio/ago. 2006.
} 
principais fatores que motivaram a escolha profissional dos professores em seu ensino superior estão relacionados a influência de um 'bom professor"”, conceito esse entendido como "aquele que consegue transmitir com clareza o que ensina, o seu domínio do conteúdo e seu conhecimento da área" (p. 3).

Falar de docência é, antes de mais nada, falar de docente, de modo que se faz necessário refletirmos inicialmente sobre tal categoria, da qual partimos. Docente é o professor que está em pleno exercício, na prática da sua atividade que é ensinar. O termo professor, por sua vez, indica a profissão exercida pelo docente, compreendido por nós como um profissional dotado de saberes e especificidades, que tem como função principal educar e mediar conhecimentos junto a seus alunos e proporcionar a ambos aprendizagem e reflexões sobre e na prática.

Nas palavras de Rios (2010, p. 53),

docência é definida como "o exercício do magistério" (Ferreira, 1975, p. 489). O docente é professor em exercício, isto é, que efetivamente desenvolve uma atividade. Ser professor é uma profissão. Mas é no efetivo exercício de sua profissão que o professor recebe a denominação de docente, particípio presente - aquele que está desenvolvendo um processo de ensinar (grifo da autora).

Ao tratar sobre esse assunto, Vieira (2016, p. 124) argumenta que "a profissão docente apresenta, desde os primórdios de sua história, características bem específicas, independentes do contexto social, político, econômico e cultural em que está inserida". $\mathrm{Na}$ fala da autora podemos observar que essa singularidade de fatores veio se moldando e moldando o ser professor ao longo dos anos, o qual, ao assumir a docência, vai constituindo sua identidade profissional, acerca do ambiente escolar e das características encontradas ao seu redor.

No contexto dessa constituição,

\footnotetext{
pode-se, também, compreender que a identidade profissional dos professores é formada por um contínuo que vai desde a fase de opção pela profissão, passando pela formação inicial, até os diferentes espaços institucionais e geracionais em que a profissão se desenrola, compreendendo o espaço/tempo em que cada um continua produzindo sua maneira de ser professor (ISAIA, 2006, p. 72).
}

E nessa maneira de ser professor estão implicados os saberes docentes, que são construídos, muitas vezes, a partir da prática, dentro do ambiente escolar, no convívio e 
exercício do magistério. Ancorado em suas experiências, o docente constitui uma bagagem de habilidades para o ensino, o que só é possível por meio da práxis. Nesse âmbito, surgem discussões sobre uma possível vocação para a docência, ao invés da escolha. No que tange a esse tema, Vieira (2016, p. 128), comenta que

\begin{abstract}
a "vocação" começa a fazer parte do contexto de atuação docente considerando que houve, pela sociedade, uma espécie de conexão da atividade de magistério a um "dom" feminino embasados no fato de que a mulher gera filhos e cuida de crianças tornando a tarefa de educar/escolarizar uma função feminina. Nesse contexto, a mulher deveria seguir sua "vocação".
\end{abstract}

Esse aspecto vocacional da profissão está ligado à sua origem história em contextos religiosos, nos quais a figura do professor era confundida com a figura do religioso, sobretudo no Brasil, onde os primeiros professores foram os padres jesuítas da Companhia de Jesus (GATTI e BARRETO, 2009). Entretanto, estudos contemporâneos em Educação apontam que a docência, assim como qualquer outra profissão, é um ofício, passível de aprendizado, desenvolvimento. Como indicam Gatti e Barreto (2009, p. 239),

\begin{abstract}
a representação da docência como "vocação" e "missão" de certa forma afastou socialmente a categoria dos professores da ideia de uma categoria profissional de trabalhadores que lutam por sua sobrevivência, prevalecendo a perspectiva de "doação de si", o que determinou, e determina em muitos casos, as dificuldades que professores encontram em sua luta categorial por salários, dificuldades estas que estão presentes no âmbito social e político, bem como na cultura intracategoria.
\end{abstract}

Nesse contexto, a demanda de ofertas de trabalho na profissão docente implica, conforme aponta Gatti (2010), a escolha pela docência como uma espécie de "seguro desemprego", ou seja, uma alternativa ao não exercício de outra atividade. Isso se apresenta como um dos motivos de ingresso em cursos de licenciaturas, sem uma reflexão sobre a motivação da escolha. E isso é inegavelmente um prejuízo, ocasionando uma crise do professorado, pois “o magistério não pode ser colocado como uma ocupação secundária" (TARDIF e LESSARD, 2005).

Sobre esse cenário, afirma-se que

a crise da profissão docente arrasta-se há longos anos e não se vislumbram perspectivas de superação a curto prazo. As consequências da situação de malestar que atinge o professorado estão a vista de todos: desmotivação pessoal e elevados índices de absentismo e de abandono, insatisfação profissional traduzida numa atitude de desinvestimento e de indisposição constante (face 
ao Ministério, aos colegas, aos alunos, etc.), recurso sistemático a discursosálibi de desculpabilização e ausência de uma reflexão crítica sobre a ação profissional etc. (NÓVOA, 1995, p. 22, grifo do autor).

Gatti e Barreto (2009, p. 240) corroboram com o delineamento dessa tensão conjuntural sobre a profissão docente dizendo que

o salário inicial de professores no geral tem sido baixo quando comparado a outras profissões que exigem formação superior [...], e isso tem peso sobre as características de procura por esse trabalho. Entre outros fatores, carreira e salários que estão associados a desprestígio profissional com certeza pesam tanto na procura por esses cursos, como sobre o ingresso e permanência na profissão.

Esses aspectos impactam não só o desempenho da carreira docente, mas, sobremaneira, a escolha por essa profissão. E tal escolha não é uma decisão exclusivamente individual, de modo que mesmo ressaltando o gosto pela profissão como principal motivador para a opção pelo magistério, os professores "não deixam de destacar outros aspectos como influência da família, questões econômicas, gosto por crianças e um desejo de transformar" (VIEIRA, 2016, p. 129).

Percebemos essa afirmação também na fala de Pereira (1999, p. 111), ao complementar argumentando que

sabe-se que o desestímulo dos jovens à escolha do magistério como profissão futura e a desmotivação dos professores em exercício para buscar aprimoramento profissional são consequência, sobretudo, das más condições de trabalho, dos salários pouco atraentes, da jornada de trabalho excessiva e da inexistência de planos de carreira.

É por meio do contato com a profissão que muitos docentes deixam a carreira do magistério, seja pelas dificuldades apresentadas no seio da profissão ou por reflexões posteriores acerca das escolhas. Nesses casos, pode a docência ser uma carreira temporária ou, diferentemente, permanente, decorrente da estabilização e identificação com as especificidades profissionais. Destacamos, assim, além das discussões de exigências na prática docente e formação dos licenciados, alguns fatores recorrentes da não escolha. Conforme indicam Freitas et al. (2010, p. 96),

O grande desafio de ser professor hoje na escola é que os problemas são tantos, o mundo está mudando tão rápido, que o professor tem que estudar não só o conteúdo, mas a metodologia de ensino, a psicologia para lidar com os alunos, ser exigente e calmo ao mesmo tempo. 
Observamos na fala desses autores que, devido às mudanças que a sociedade vem vivenciando, o professor deve estar atualizando-se constantemente para acompanhá-las. Como uma dessas mudanças, podemos destacar a globalização, que tem exercido influência na Educação de modo geral. Nunca os professores foram tão cobrados por parte das escolas e da sociedade, de modo geral, como nas últimas décadas, a fim de resultados condizentes com o perfil de indivíduo que se espera para o mundo globalizado.

De sorte que a sociedade atualmente anseia que as escolas sejam responsáveis pelos alunos, não só no âmbito da instrução, mas também no que diz respeito à educação, formação para as demandas sociais contemporâneas, e ao desenvolvimento de habilidades para o mundo do trabalho, que se atualizam constantemente. Recai, então, sobre o docente a responsabilização pelos resultados e a tarefa de procurar meios alternativos de ensino, que não sejam os mesmos utilizados em contextos anteriores, o que é, sem dúvida, um desafio.

Uma questão nesse processo de escolha se deve ao fato de que é ainda no ambiente escolar que a maioria dos jovens decide suas opções de cursos. $\mathrm{Na}$ interação com os colegas e com profissionais de variadas áreas constitui-se uma imagem de si, muitas vezes baseada em poucas evidências concretas sobre as realidades das profissões. Afinal, são essas "representações individuais sobre uma atividade ou característica que constituem uma imagem de si, ou seja, as experiências que as pessoas mobilizam no momento de realizarem suas escolhas são produtos dessa interação entre o individual e o social num processo de socialização" (DUBAR, 2005 apud SOUZA, 2012, p. 9).

Ao escolher um curso de licenciatura deve-se conhecer os aspectos que envolvem tal carreira profissional, tanto para o melhor desenvolvimento pessoal dentro da profissão, quanto para uma maior contribuição à área educacional, na qual se insere a docência. Na opção por cursar uma licenciatura em área específica como, por exemplo, a Matemática, ou outras áreas, muitas vezes, os alunos não têm a expectativa de serem professores, mas sim matemáticos (SOUZA, 2012).

Nesse sentido, Lima, Santos e Borges Neto (2010), ressaltam as diferenças entre o matemático e o licenciado em Matemática (Quadro 1). Mesmo que pareça trivial, como se disséssemos o óbvio, o insistente interesse pela profissão de matemático em alunos de licenciatura faz necessário reforçar o objetivo dos cursos de formação inicial de 
professores, que é, como o próprio nome indica, habilitar profissionais para o ensino.

Quadro 1: Principais diferenças entre o Matemático e o Licenciado em Matemática

Matemático (Bacharel em Matemática)

É o profissional que vê o seu trabalho como parte inerente a estrutura do mundo que o cerca, cujo produto de suas investigações são verdades válidas para sempre, cuja legitimação ocorre por meio de demonstrações rigorosas, que as tornam incontestáveis e convincentes.

\section{Professor (Licenciado em Matemática)}

É o profissional que tem domínio do conhecimento matemático e o utiliza como meio, direcionando suas atividades com objetivo de formar o cidadão. É de sua responsabilidade a formação educacional e social do estudante

Fonte: Adaptado a partir de Lima, Santos e Borges Neto (2010, p. 49-50)

Devido às políticas de inclusão nas universidades, as possibilidades de cursos de Ensino Superior expandiram-se para a população de classes mais pobres, sobretudo no que diz respeito às licenciaturas. Isso porque "além de ser um curso com um número elevado de vagas, tanto nas instituições públicas quanto privadas, é uma profissão que desperta pouco interesse nos jovens de famílias mais abastadas devido ao seu baixo status social e econômico na atualidade" (SOUZA, 2012, p. 5).

Nesse contexto, como apontado por Gatti (2014, p. 160), a maioria dos cursos de licenciaturas está nas instituições privadas de Ensino Superior, e, ainda, "o crescimento das matrículas nos cursos que formam professores vem sendo proporcionalmente muito menor do que o crescimento constatado nos demais cursos de graduação". No que se refere especificamente à Matemática, dados de 2009 indicam que as regiões Sul e Sudeste são as principais formadoras de professores nas instituições privadas, enquanto no Nordeste, o maior número de matrículas para professores de Matemática está nas instituições públicas (GATTI e BARRETO, 2009). Em âmbito nacional, pesquisas mais recentes apontam que cerca de $70 \%$ das matrículas nos cursos de Licenciatura em Matemática são em instituições públicas (GATTI et al., 2019).

Após esse delineamento do contexto da profissão docente, suas questões envolvendo a escolha e permanência, seguimos com o aprofundamento nesta pesquisa, a partir dos aspectos metodológicos e dos resultados obtidos e suas análises.

\section{Percurso metodológico da pesquisa}

Tendo em vista seu foco de análise, estilo discursivo e interpretação das entrevistas, consideramos esta uma pesquisa qualitativa, constituída a partir de um estudo de caso. Em consonância com a abordagem e o tipo de pesquisa escolhidos, temos, 
segundo Fiorentini e Lorenzato (2007, p. 110), que "o estudo de caso tende a seguir uma abordagem qualitativa. Mas isso não significa abandonar algumas quantificações necessárias. Essas quantificações podem ajudar a qualificar melhor uma análise". Ao tratar sobre o tipo de estudo utilizado para a produção deste trabalho, os autores argumentam, ainda, que "o estudo de caso busca retratar a realidade de forma profunda e mais complexa possível, enfatizando a interpretação ou análise do objeto, no contexto em que ele se encontra" (FIORENTINI e LORENZATO, 2007, p. 110).

Desse modo, constituiu-se como caso a ser estudado o grupo de egressos do curso de Licenciatura em Matemática da FECLESC/UECE, no interior do Ceará, nosso lócus de pesquisa. Tendo sido implantado em 2002, o curso completou, em 2017, 15 anos de funcionamento, sendo esse o recorte temporal trabalhado. De modo que, entre a primeira turma de formados, de 2006, e a última referente ao ano de 2016, há um total de 91 licenciados (Tabela 1).

Tabela 1: Quantitativo de licenciados pelo curso em estudo por semestre

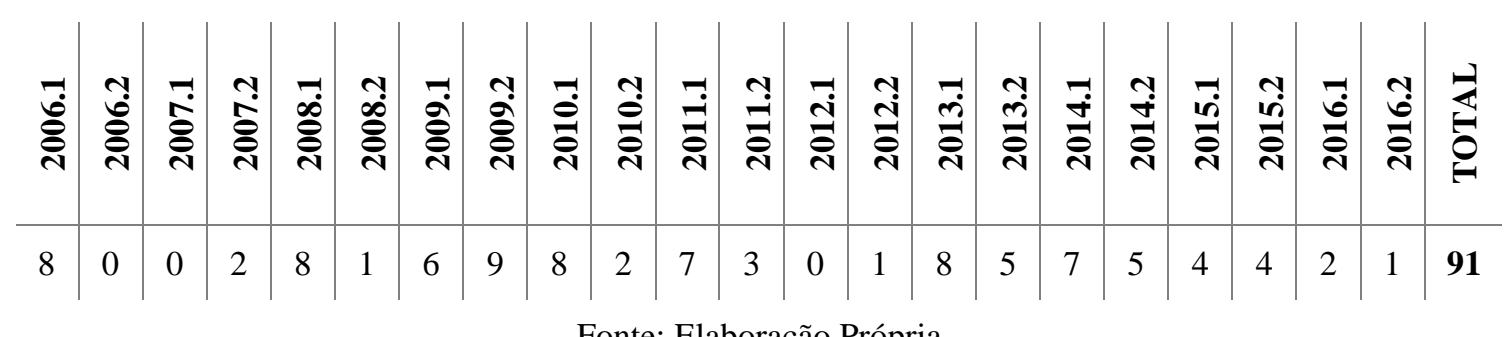

Fonte: Elaboração Própria

Na composição do quadro de sujeitos da pesquisa, operou-se da seguinte maneira: em contato com o Controle Acadêmico do campus, obtivemos os nomes completos dos 91 egressos, e mais informações adicionais de alguns destes (e-mail e/ou telefone para contato); após, partimos a campo, a fim de localizar e contactar esses egressos, por meio de contatos, conhecidos em comum, redes sociais etc. Dos 76 localizados, após a explicação e convite para a pesquisa, apenas 50 deram retorno positivo, sendo, finalmente, esses os participantes do estudo.

Como instrumento de levantamento de dados utilizamos um questionário, elaborado na modalidade mista, contendo 15 perguntas, das quais 5 abertas e 10 fechadas, sendo estas últimas compostas por um conjunto de alternativas para melhor escolha do participante. No rol das alternativas fechadas também constava a opção “outros", para que o sujeito expressasse sua opinião, caso esta não correspondesse a nenhuma das 
apresentadas. A aplicação se deu por formulário eletrônico, divulgado por meio dos emails e redes sociais dos egressos, em uma árdua busca pelo retorno de parte dos depoentes.

A primeira parte do questionário, que visava à identificação dos sujeitos, revelou que estes possuem idade variando de 20 a 45 anos, uma amostra relativamente jovem, sendo a faixa etária mais recorrente a de 25 a 35 anos. Quanto à titulação, tem-se alguns apenas graduados (15), outros tantos especialistas ou cursando especialização (25, a maioria), uns poucos mestres ou mestrandos (8) e doutores ou doutorandos (2).

Ainda nessa etapa, a fim de identificar a experiência docente que tinham os sujeitos, perguntou-se o tempo em sala de aula, independentemente de estar ou não atuando atualmente como docente. Como resposta obtivemos que 5 não possuem experiência alguma; 11 possuem até quatro anos de ensino; 22 possuem de cinco a dez anos; e 12 possuem mais de dez anos de carreira docente.

Como recomendado pela Resolução nº 510/2016 do Conselho Nacional de Saúde, em se tratando de um estudo com seres humanos, mesmo que com aspectos quantitativos, o questionário era acompanhado de um preâmbulo explicativo, no qual constava os objetivos e riscos da pesquisa, bem como as responsabilidades e concessões ao pesquisador. Nesse espaço, ainda, figurava uma opção na qual o pesquisado concordava ou não em compartilhar suas respostas, estando ciente da publicação da pesquisa e da garantia do anonimato, nesse caso. Somente foram consideradas as respostas nas quais constava essa anuência, o que não reduziu o número de participantes.

Para interpretação dos dados obtidos utilizamos da teoria de Bardin (2011), nas três fases da Análise de Conteúdo apontadas pela autora: i) pré-análise, ii) exploração do material e iii) tratamento dos resultados, inferência e interpretação. Tal escolha e deu por concordarmos que "operações estatísticas simples (porcentagem), ou mais complexas (análise fatorial), permitem estabelecer quadros de resultados, diagramas, figuras e modelos, os quais condensam e põem em relevo as informações pela análise" (BARDIN, 2011, p. 131), isso pois “o analista, tendo à sua disposição resultados significativos e fiéis, pode então propor inferências e adiantar interpretações a propósito dos objetivos previstos" (BARDIN, 2011, p. 131). 


\section{Resultados e discussões}

Os dados levantados com a aplicação do questionário, especificamente com a segunda etapa de perguntas, nos possibilitam descrever alguns elementos que caracterizam a escolha pelo curso, o percurso na graduação, a experiência com a docência, antes, durante e depois da formação inicial e outros. As análises feitas em torno de tais aspectos nos auxiliaram a alcançar o objetivo almejado na pesquisa.

Quando indagados sobre a principal razão que os levou à escolha pelo curso de licenciatura em questão, 46 egressos atribuíram suas escolhas ao fato de se identificarem com a disciplina Matemática, 6 apontaram falta de opção como o motivo e outros 6 assinalaram a opção "outros", nesses casos citando o curso como uma forma de preparação para concursos, por ser a Matemática uma disciplina complexa. Ressaltou-se, ainda, a escolha pelo fato de ser o curso mais "temido", à época, sendo considerado um desafio cursá-lo, além das condições financeiras que não permitiam concorrer para outras possibilidades de graduação.

Percebe-se que a escolha da licenciatura nessa área do saber se deu pela identificação com a disciplina. Verifica-se, também, que um dos sujeitos considerou o curso mais acessível e outro considerou o vestibular o mais fácil. Em relação a essa facilidade, importa destacar que não se trata da Matemática, em si, pois essa é notadamente considerada uma disciplina difícil (MASOLA e ALLEVATO, 2019), mas, sim, ao fato de a procura por esse curso ser pequena, acarretando uma baixa concorrência. Cenário que corresponde ao panorama nacional, no qual há considerável oferta de cursos de Matemática, mas baixo número de matrículas (GATTI e BARRETO, 2009).

Em seguida, questionou-se a respeito da experiência docente dos sujeitos antes da graduação, obtendo-se como resposta que 14 desempenharam a função de professor antes de obter habilitação, enquanto 36 não, nunca haviam assumido uma sala de aula. Indagouse também quanto à inserção na vida profissional ao longo do curso de formação inicial, tendo como resultado que 40 dos entrevistados desempenharam a docência durante a graduação e 10 continuaram sem essa experiência nos anos que fizeram o curso.

Fazendo um comparativo antes e durante a graduação, vemos uma considerável diferença entre os que exerciam a docência antes de ingressar e após o ingresso no curso. 
Aqueles que atuaram antes do ingresso permaneceram durante a graduação e alguns dos que não haviam exercido tiveram a oportunidade de viver a experiência durante seu período na licenciatura. Isso evidencia a carência de professores na região e a demanda por professores de Matemática, antes mesmo da conclusão de sua formação inicial.

Nota-se que tal carência figura os municípios no interior do Ceará, incluindo as cidades do Sertão Central e da região do Maciço de Baturité, as duas regiões geográficas mais atendidas pela faculdade em estudo. Cruzando os dados obtidos pelo questionário, é possível perceber que a maioria dos egressos começou a atuar na docência ainda muito jovem, com a idade média entre 25 e 35 anos. Isso justifica-se, também, pelo fato de alguns já terem exercido a docência sem a formação acadêmica apropriada.

Devido às reformas educacionais exigidas pela LDB vigente, lei nº 9.394/96, aqueles que atuavam no magistério sem serem habilitados tiveram que buscar uma formação em nível superior para poder exercer a docência na Educação Básica. A esse tempo diversos cursos foram criados e oferecidos em todos os municípios cearenses, alguns deles existentes até o momento da pesquisa.

Durante a graduação é comum que nos deparemos com situações positivas ou negativas em nosso processo formativo. Com o intuito de saber a experiência dos sujeitos nesse sentido e suas possíveis implicações nas escolhas profissionais feitas a posteriori, foi questionado sobre as principais dificuldades encontradas durante sua trajetória na universidade. Como resposta obtivemos que:

\footnotetext{
A maior dificuldade é a adaptação ao estudo da matemática de forma rigorosa, com demonstrações, encadeamento lógico de ideias e tudo mais. Tal dificuldade foi acentuada pela falta de base dos conteúdos básicos do ensino médio (A. J., grifo nosso)

Dificuldades em acompanhar algumas disciplinas do curso e principalmente as disciplinas do curso de Física. Sem falar nas greves que tive que enfrentar e a falta de professores (F. A., grifo nosso).

Dificuldades referente a locomoção, pois morava e trabalhava na cidade de S. P. que ficava a $120 \mathrm{~km}$ distante de Q. [nomes suprimidos em função do sigilo]. $\mathrm{Na}$ infraestrutura e na falta de corpo docente para dar conta de todas as disciplinas (R. L., grifo nosso).

A principal dificuldade é que o currículo do curso de licenciatura em matemática é desconectado da realidade vivenciada em sala de aula; de forma alguma, exceto, no conhecimento de conteúdo específicos da disciplina, contribui para sua função principal que é a formação de professores de matemática, na realidade o curso me formou para ser bacharel em matemática e não licenciado (F. L., grifo nosso) (grifos nossos).
} 
Notadamente há a necessidade de que a acolhida dos alunos recém-chegados ao Ensino Superior seja também no sentido de identificar quais as fragilidades e lacunas esses trazem em suas bagagens formativas. Os saberes que possuem são implicações dos conhecimentos que adquiriram na Educação Básica e é possível que suas dificuldades façam com que se percam durante o processo de graduação, podendo vir a causar até mesmo a desistência, pelo sentimento de incapacidade em aprender.

Seguindo com nossa análise, é sabido que a carreira docente carrega um caráter histórico, tendo ganhado, ao longo dos anos, diferentes significados perante a sociedade. O docente sempre foi e até hoje é visto por muitos como aquele dotado do saber. Ao passo que a formação dos professores que ensinam Matemática (PEM) tem sido pauta das discussões e pesquisas sobre o desenvolvimento profissional desse docente. Considerando isso e com o intuito de averiguar os posicionamentos quanto às discussões sobre formação e valorização profissional, indagou-se aos egressos sobre suas concepções acerca do que é ser professor de Matemática.

Como se sabe, a Matemática não é uma das disciplinas favoritas dos alunos, seja em escolas públicas ou particulares. O fato de os alunos não gostarem dessa disciplina é um problema que recai continuamente na figura do professor. De forma que, muitas vezes, o ser professor é considerado sob um outro aspecto pelos alunos e mesmo pela sociedade. Essa afirmação pode ser confirmada na resposta do egresso W. B. à questão previamente mencionada:

\begin{abstract}
Um profissional que vai ser odiado pelo simples fato de ensinar a matemática, que além de se preocupar com técnicas e métodos de ensino, terá também que pensar uma maneira de fazer seus alunos perderem o medo de estudar matemática. Que sempre será criticado pela direção da escola, mesmo que você seja o melhor professor do mundo, a não ser que todos os alunos sejam aprovados. Olhando para os aspectos positivos, somos agentes transformadores, pois ajudamos as pessoas a desenvolverem a habilidade de raciocinar e de resolver problemas em geral (W. B.).
\end{abstract}

Perez (1999), em consonância, considera o professor de Matemática como o principal mediador entre os estudantes e os conhecimentos matemáticos historicamente produzidos ao longo do tempo. É, dessa forma, um dos grandes responsáveis por possíveis transformações, tanto no ambiente escolar como na sociedade.

O questionamento seguinte diz respeito à atuação dos sujeitos no período de 
realização da pesquisa. A partir dos dados, verificamos que 36 estão atuando na docência, sendo 29 no exercício do magistério e 7 em cargos de gestão. Os outros 14 egressos não estão exercendo o magistério, dentre os quais estão os que não escolheram seguir essa carreira e um que está desempregado.

De modo que, retomando a questão, é possível apontar que a carência de professores na área de Matemática na região foi sistematicamente reduzida, pois até o momento da pesquisa 91 licenciados em Matemática foram devidamente habilitados para o ensino. Considerando que mais da metade desses está na docência, como apontado neste escrito, além dos que, mesmo não estando em sala de aula, atuam junto à Educação, vêse que a demanda foi significativamente atendida.

Ainda nesse âmbito de atuação na docência, perguntas complementares foram feitas, a fim de identificar o contexto no qual esses docentes atuam, especificamente no que diz respeito à rede de atuação, nível de ensino e disciplinas que ministra. Do apurado, 35 estão atuando na rede pública e 3 estão atuando na rede particular, ressaltando, ainda, que há aqueles que exercem a função de docente e de gestor em ambas as redes educacionais.

Como apontado por Tardif e Lessard (2005), os profissionais do ensino se destacam como um dos principais grupos ocupacionais, pelo fato de constituírem uma das maiores ocupações de empregos gerados no país, por serem os profissionais do saber e possuírem o alto nível de escolaridade, no caso em nível superior. Sabe-se, ainda, que a maior concentração dos empregos docentes está na Educação Básica, que abrange os Ensinos Infantil, Fundamental e Médio.

Entre os 36 respondentes que estão atuando na docência e/ou gestão escolar, 27 atuam no Ensino Médio, o que totaliza mais da metade dos docentes; 15 estão nos Anos Finais do Ensino Fundamental; 3 estão no Ensino Superior e 2 estão nos Anos Iniciais do Ensino Fundamental, estes últimos em um nível para o qual não foram habilitados. Ressaltamos que entre os participantes há aqueles que possuem dois ou mais vínculos institucionais.

Indagou-se, ainda, aos 29 atuantes na docência, se lecionam apenas a disciplina de Matemática ou também outras, uma vez que é comum, devido à carência de docentes, vê-se professores ensinando matérias diferentes das/para as quais foram habilitados. 
Nesse sentido, 16 assinalaram que lecionavam apenas Matemática e 13 ensinavam, também, outras disciplinas, das quais as mais apontadas foram Física e Ciências Naturais, mas também figuraram na lista Química, Geografia, Educação Física e Ensino Religioso.

Em relação aos fatores que levaram os egressos do curso de Matemática a optarem pela docência - no caso dos que, de fato, fizeram essa opção —, 24 atribuíram a escolha ao gosto pela profissão. Dentre os outros fatores, 5 dos egressos acreditam que a docência possibilita uma maior facilidade de emprego. Em ordem vem a opção "outros" com 3, enquanto 2 dizem ter escolhido por causa do incentivo da família e 1 acha o salário de professor atrativo. Esses dados vão ao encontro do que afirma Kozelski (2014, p. 181), ao dizer que a "escolha pela carreira docente é marcada pela idealização dos pais que influenciam seus filhos na busca de carreiras mais valorizadas".

É evidente que a identificação pela profissão docente pode ter sido fortalecida no decorrer do processo de graduação, pelo conhecimento e exercício da prática pedagógica vivenciada em seu processo contínuo de formação, além das experiências vivenciadas no exercício do magistério. Como foi citado anteriormente, grande parte dos egressos vivenciaram a docência antes ou durante a graduação.

Ao analisar os fatores que levaram os 14 egressos a não escolher a docência como profissão a ser seguida, verificamos que 6 assinalaram a opção "outros" e registraram fatores diferentes daqueles listados no item. A partir do apontado, podemos constatar que a maioria não assumiu a docência por ter sido aprovado em concurso público para outra área, outro campo profissional. Outro fato considerável para a não escolha pela docência está ligado à baixa remuneração, tendo sido o caso de 2 dos respondentes. Igualmente, 2 assinalaram não ter escolhido a carreira como docente devido a proposta de emprego considerada melhor, levando em conta a questão salarial atribuída a outras profissões.

Algumas literaturas corroboram com esses dados como, por exemplo, Gatti (2009), que nos diz sobre a percepção acerca do custo/benefício da carreira docente não motivar a permanência no magistério. Para essa autora, a baixa remuneração e, principalmente, a falta de reconhecimento, fazem com que os professores desistam de exercer a docência, pois trabalham muito e ganham pouco. Estes são aspectos relevantes para a desistência da carreira, mesmo que em algum momento tenha havido o desejo de segui-la (GATTI, 2009). 
As dificuldades são presentes quando se fala a respeito da realidade educacional da atualidade, visto que 2 dos sujeitos assinalaram que encontraram diversos problemas com a experiência em sala aula, o que os levaram à desistência da profissão docente. Em relação a falta de afinidade pela profissão, um é recorrente, o que nos leva a concluir que é resultado da falta de opção no momento da escolha do curso ou de uma escolha equivocada.

Gatti (2009) justifica essa pouca ou quase nenhuma atração pela docência por gostar de outras profissões ou considerar que existem atividades mais interessantes em outros ramos, que não quer permanecer em ambiente escolar e que a carreira não agrega possíveis mudanças de cargos como nas empresas. Entre os licenciados, um assinalou, ainda que há dificuldades de emprego na profissão docente, e tal dificuldade pode estar relacionada ao local onde residem.

É perceptível que a identificação com a profissão docente nem sempre ocorre antes da escolha do curso. Existem múltiplos fatores que levam a essa tomada de decisão. Em muitos casos, isso se dá ainda no processo de formação, podendo este mudar a concepção sobre a docência, em si, e a escolha por essa. Outras vezes, a inclinação só se dá durante o exercício do magistério, dependendo do envolvimento do docente com a profissão escolhida ou não.

Atualmente, no Brasil, os professores são oriundos de camadas sociais menos favorecidas social e educativamente (GATTI e BARRETO, 2009). Essas condições vêm comprometendo sua bagagem educacional, pois limitam as possibilidades de criar alternativas para lidar com os fenômenos educativos. Tais questões estão ligadas à formação inicial e continuada desse professor, bem como ao seu desenvolvimento profissional, à necessidade de planos de carreira dignos e à valorização social.

Foi solicitado aos egressos que relatassem se a disciplina de Estágio Supervisionado, componente curricular obrigatório às licenciaturas, teve alguma influência em sua escolha pela docência. Os dados mostram que 30 concordam com essa influência, enquanto 20 discordam. Ou seja, mais da metade dos participantes consideram que o Estágio foi importante na sua escolha pelo magistério. As percepções daqueles que afirmaram que o Estágio influenciou na sua escolha pela docência são diversas, e podemos conferir duas delas nos relatos a seguir: 
Tive bons e maus momentos nos meus estágios. E considero importante essa disciplina, pois permite conhecer de perto a vida escolar e conviver com seus diferentes elementos: alunos, que muitas vezes eram desinteressados, também se mostravam motivados quando acertávamos no estímulo e na forma de ensinar; professores, não raro, eram desanimados, financeiramente descontentes, alguns até depressivos e sem nenhum interesse por sua profissão, contudo, havia os que contavam histórias de superação e do quanto se doavam a tarefa de educar; quanto a infraestrutura, havia ausência de bons laboratórios. Não vou negar que essas dificuldades assustam um estagiário. Mas prefiro vê-las como um desafio para os futuros educadores, essa é a realidade e é a partir dela que se deve trabalhar. $O$ estágio deu-me a oportunidade de conhecer minhas limitações e apontou direções que eu deveria seguir, caso desejasse aperfeiçoar-me como professor. Foi durante ele, que despertei o desejo de experimentar outras profissões, ao menos temporariamente. Isso me levou a outra carreira profissional, e até o momento não retornei para a sala de aula (A. D., grifo nosso).

O contato direto com a escola e, principalmente, com os alunos influencia bastante na opção pela profissão; no meu caso como meu primeiro contato em sala de aula foi no estágio, não há dúvidas de que influenciou e muito na minha escolha (F. G., grifo nosso).

Muitas vezes, como indicado no último trecho, é por meio do Estágio que os alunos de licenciaturas têm um primeiro contato com a sala de aula nas escolas públicas. No entanto, o Estágio, por si só, não é capaz de transformar o aluno em professor, de uma hora para outra. É para além das experiências advindas dos estágios, das vivências enquanto aluno e da própria formação que se constitui o professor. Afinal,

Não nos tornamos professores da noite para o dia. Ao contrário, fomos constituindo essa identificação com a profissão docente no decorrer da vida, tanto pelos exemplos positivos, como pela negação de modelos. É nessa longa estrada que vamos constituindo maneiras de ser e estar no magistério (LIMA, 2012, p. 39).

Colocando em foco as políticas educativas, um dos programas que têm impactado a formação docente e a permanência dos alunos nos cursos de licenciaturas é o Programa Institucional de Bolsas de Iniciação à Docência, o PIBID, criado pelo decreto ${ }^{\circ}$ 7.219, de 24 de junho de 2010. Este Programa, citado em diversas respostas do questionário aplicado, é desenvolvido pela Coordenação de Aperfeiçoamento de Pessoal de Nível Superior (CAPES), que concede bolsas a licenciandos, em função do desenvolvimento de atividades, experiências e contato com escolas da Educação Básica, acompanhados por docentes em pleno exercício do magistério.

De acordo com Gatti, Barreto e André (2011), citadas por Gatti (2015), o PIBID é um dos programas recentes que vem mostrando efeitos positivos, contribuindo aos 
alunos ainda na permanência nos cursos de licenciatura. Sua limitação recai ao número de bolsas que oferece, limitando-se a apenas alguns alunos dos cursos e não sua totalidade.

Questionou-se, em seguida, aos egressos como eles percebem a profissão professor no atual contexto social, político, econômico e cultural do século XXI. Algumas respostas relatam a complexidade da atual situação da carreira docente, como explicita os seguintes depoimentos:

\begin{abstract}
No contexto atual, a profissão docente é desafiadora. É preciso lidar com a falta de valorização social dos docentes por parte de muitos segmentos, com a transferência de responsabilidade da família para a escola, com precárias condições de trabalho em muitas escolas do país, com a desmotivação da própria classe docente. No enfrentamento dessas questões, fará a diferença o compromisso do professor com a sua profissão, de modo a permanecer lutando contra todas as desfavoráveis condições que o cercam (A. C., grifo nosso).

Estamos vivenciando um câncer na educação, por não ter uma política voltada para a valorização do professor, isso infere no fator econômico, com isso bons professores desviam o foco e migram em outras profissões, acarretando assim professores frustrados, que só sabem ensinar, e não têm o prazer de ser inovador, deixando de ser a bela figura de um professor na sociedade (F. W., grifo nosso).
\end{abstract}

O professor, compromissado com a realidade educacional, entende que é sujeito do processo educativo e um dos principais colaboradores na aquisição e mobilização do conhecimento. Todavia, há, ainda, uma interação com o mundo e as condições da sociedade que os cercam, seguido por desafios constantes, estando o docente inserido no contexto social, político, econômico e cultural.

A profissão docente é, seguramente, uma das mais desvalorizadas, a começar pelo próprio professorado, sendo o magistério atualmente buscado por pessoas que não têm formação específica ou, ainda, por aquelas que não conseguiram alcançar a profissão almejada. Estes fatores acarretam uma crise na formação de professores do século XXI e, por consequência, na identidade profissional dessa categoria. $\mathrm{O}$ perfil dos profissionais da Educação tem sido objeto das recentes discussões e reflexões em políticas públicas educacionais, quando se discute sobre o papel do educador e a formação ideal diante do contexto da contemporaneidade.

A profissão de professor é a mais importante de todas, porque forma todas as outras. A nossa profissão sempre foi desvalorizada em relação a salário. Nas escolas públicas o material que tem às vezes não supre as necessidades dos professores na condução das aulas, onde alguns professores tiram do próprio bolso 
para não deixar o seu trabalho parar e ter como ministrar as suas aulas e educar muito bem a população da cidade que ele trabalha. Acho que é por isso que a profissão de professor e uma das menos procuradas atualmente pelos jovens (W. V.).

É recorrente aos docentes as dificuldades encontradas nas escolas, nas salas de aulas, assim como são imprevisíveis as situações que esses irão encontrar em seu dia a dia. De modo que uma busca incansável à procura de métodos adequados para uma melhor aprendizagem dos alunos se faz necessária, o que não fica tão longe da complexidade das exigências dos conteúdos a serem ensinados.

A procura de melhores formas de alcançar o aprendizado dos conteúdos propostos nos currículos nem sempre é efetivada, devido à falta de recursos para promover atividades que são aparentemente simples, mas transformadoras no ambiente escolar. Entretanto, é possível que haja, ainda, uma recusa do professor em renovar-se para a transmissão de conteúdos, adaptando-se, por exemplo, ao uso de novas tecnologias. Isso faz com que os docentes ensinem da mesma forma que lhes foi ensinado, sem que haja uma reflexão na e sobre sua prática.

Os dados desta pesquisa nos permitem ver que os egressos percebem a profissão docente como desvalorizada, tanto pela falta de incentivos financeiros como a precarização nas condições de trabalho e na estrutura escolar. Os comentários são baseados em suas próprias experiências docente, pois vivenciam (ou vivenciaram) diversos problemas e desafios da profissão.

É pertinente salientarmos, nesse sentido, que "hoje os professores sinalizam o quanto carregam para si a culpa dos fracassos dos alunos, da escola e da educação como um todo" (GONÇALVES e FIORENTINI, 2005, p. 101). Contudo, buscam melhorias para sua classe, mudanças nas condições de trabalho e, sobretudo, um prestígio social da função desempenhada na sociedade.

Ao questionarmos aos egressos quanto à escolha do curso de Matemática, percebemos que a opção se deu principalmente pelo fato da identificação com a Matemática. Nesse âmbito, os participantes foram finalmente indagados se fariam novamente a opção pela licenciatura em Matemática, se lhes fosse possível voltar no tempo. Consideráveis 43 afirmaram que escolheriam novamente o curso de Matemática, ao passo que 7 dos participantes responderam que não o escolheriam. Tais dados mostram 
que os professores representados nesse último percentual não estão plenamente satisfeitos com a sua formação inicial e/ou profisssão.

Uma das questões a serem consideradas no Ensino Superior, sobretudo na formação inicial docente, é a preparação dos futuros professores para atuar e lidar com as diversas situações encontradas no dia a dia da escola. Faz-se necessário, desse modo, que, durante a graduação, os alunos tenham conhecimento suficiente para entender o espaço escolar e estejam preparados para enfrentar obstáculos em sua carreira profissional (OLIVEIRA e SOUZA, 2017).

Todos estes aspectos apresentados pelos egressos no decorrer da pesquisa nos levam a refletir sobre até que ponto o curso de Licenciatura em Matemática oferece oportunidades, por meio de suas disciplinas curriculares e espaços formativos, para que o profissional nele formado prepare-se adequadamente para exercer a profissão e lidar com diversos conflitos das políticas educacionais, mantendo-se atuante e satisfeito com a profissão.

\section{Considerações Finais}

A instituição de formação inicial estudada assumiu, nos últimos 15 anos, o papel de formadora dos novos profissionais para o ensino de Matemática na Região do Sertão Central cearense. O presente estudo nos revelou, a partir dos depoimentos dos egressos participantes da pesquisa, que a opção pela carreira docente é marcada por múltiplos fatores, uma vez que escolher a docência ou adotá-la como atividade profissional é carregar incertezas. Tornar-se professor é também passar por diversas experiências e situações desafiadoras, que muitas vezes fazem repensar sobre tal escolha.

A pesquisa mostrou-nos também que os motivos de interesses pela docência surgem ainda na escolha pelo curso de nível superior. Muitas vezes ao optar por um curso de licenciatura, o sujeito não tem clareza sobre sua decisão quanto à docência. Ficou igualmente evidenciado que a opção pela docência está ligada ao gosto pela profissão, influência familiar, facilidade de emprego, entre outros aspectos. Mas pode estar ligada, ainda, à necessidade financeira decorrente da situação socioeconômica. Dados mostram que quase todos os participantes (46) aderiram ao curso, sobretudo, por se identificarem com a disciplina Matemática.

No entanto, dos 50 egressos, apenas 29 estão atuando na docência e 7 em cargos 
de gestão escolar. O percentual dos que não estão na docência é de 30\%, dos quais 14 egressos não optaram pela docência e um está desempregado. Dentre os fatores que motivaram ao desinteresse pela profissão docente estão, segundo os sujeitos, o salário baixo, a dificuldade de emprego, a falta de afinidade com a profissão, melhores propostas de emprego e outros.

Quanto aos egressos que estão atuando na educação, sejam docentes ou gestores escolares, estes declaram gostar da profissão, mas apontam as dificuldades presentes na carreira docente. Esses professores necessitam de motivação constante para enfrentar e permanecer no magistério. Os achados revelam ainda a insatisfação que muitos dos egressos têm pela carreira docente, o que é comum diante a realidade vivenciada no Brasil, nas políticas públicas em educação, no âmbito social, econômico e cultural. Buscase melhorias e valorização profissional, através de reivindicação salarial, prestígio social e reconhecimento pelo papel que desempenha perante a sociedade.

A partir do exposto, cabe a nós refletir sobre a inserção no magistério e os desafios da educação. Ao passo que cabe às instituições de ensino e aos professores formadores incentivar para o ingresso e permanência de seus alunos no magistério. Afinal, o curso de licenciatura, de acordo com a legislação vigente, tem por finalidade formar professores para atuarem na Educação Básica, devendo, assim, contemplar em suas ações a construção e o fortalecimento da permanência de seus alunos quanto ao desenvolvimento de saberes inerentes à atividade docente, pois é nesse contexto, de escolha e atuação na profissão, que o sujeito acaba permanecendo ou não na docência.

\section{Referências}

BARDIN, Laurence. Análise de Conteúdo. Tradução de Luís Antero Reto e Augusto Pinheiro. São Paulo: Edições 70, 2011.

FIORENTINI, Dario; LORENZATO, Sergio. Investigação em Educação Matemática: percursos teóricos e metodológicos.2. ed. Campinas: Autores Associados, 2007.

FREITAS, Maria Tereza Menezes; NACARATO, Adair Mendes; PASSOS, Carmen Lúcia Brancaglion; FIORENTINI, Dario; ROCHA, Luciana Parente; MISKULIN, Rosana Giaretta Sguerra. O desafio de ser professor de matemática hoje no Brasil. In: FIORENTINI, Dario; NACARATO, Adair Mendes. (Org.). Cultura, formação $e$ desenvolvimento profissional de professores que ensinam matemática: investigando e teorizando a partir da prática. São Paulo: MUSA, 2010, p. 89-105. 
GATTI, Bernadete Angelina. A atratividade da carreira docente no Brasil. São Paulo: Fundação Victor Civita, 2009.

GATTI, Bernadete Angelina. Formação de professores: licenciaturas, currículos e políticas. Movimento: Revista de Educação, Niterói, v. 2, n. 2, p. 1-18, 2015.

GATTI, Bernadete Angelina; BARRETO, Elba Siqueira de Sá. Professores do Brasil: impasses e desafios. Brasília: UNESCO, 2009.

GATTI, Bernardete Angelina. A formação inicial de professores para a Educação Básica: as licenciaturas. Revista USP, n. 100, p. 33-46, 2014.

GATTI, Bernardete Angelina; Barreto, Elba Siqueira de Sá; ANDRÉ, Marli Eliza Dalmazo Afonso de; ALMEIDA, Patrícia Cristina Albieri de. Professores do Brasil: novos cenários de formação. Brasília: UNESCO, 2019.

GONÇALVES, Tadeu Oliver; FIORENTINI, Dario. Formação e desenvolvimento profissional de docentes que formam matematicamente futuros professores. In: FIORENTINI, Dario; NACARATO, Adair Mendes (Org.). Cultura, formação $e$ desenvolvimento profissional de professores que ensinam Matemática: investigando e teorizando a partir da prática. São Paulo: MUSA, 2005, p. 68-88.

ISAIA, Silvia Maria de Aguiar. Desafios à docência superior: pressupostos a considerar. In: RISTOFF, Dilvo; SEVEGNANI, Palmira (Org.). Docência na educação superior. Brasília: Instituto Nacional de Estudos e Pesquisas Educacionais Anísio Teixeira, 2006.

KOZELSKI, Adriana Cristina. Professor: uma carreira em extinção ou falta de motivação? Revista Intersaberes, Curitiba, v. 9, n. 17, p. 178-188, jan. 2014.

LIMA, Ivoneide Pinheiro de; SANTOS, Maria José Costa dos; BORGES NETO, Hermínio. O matemático, o licenciado em Matemática e o pedagogo: três concepções diferentes na abordagem matemática. Revista de Matemática, Ensino e Cultura, Belém, v. 5 , n. 6 , p. $42-52$, jan. 2010.

LIMA, Maria Socorro Lima. Estágio e aprendizagem da profissão docente. Brasília: Liber Livro, 2012.

MAZOLA, Wilson de Jesus; ALLEVATO, Norma Suely Gomes. Dificuldades de aprendizagem matemática: algumas reflexões. Educação Matemática Debate, Montes Claros. v. 3, n. 7, p. 52-67, jan./abr. 2019.

NÓVOA, Antonio. O passado e o presente dos professores. In: NÓVOA, Antonio (Org.). Profissão professor. 2. ed. Portugal: Porto Editora, 1995, p. 13-34.

OLIVEIRA, Cristiane Coppe de; SOUZA, Anderson. Planejamento escolar na concepção docente: uma reflexão sobre a práxis pedagógica. Educação Matemática Debate, Montes Claros, v. 1, n. 2, maio/ago. 2017.

PEREIRA, Júlio Emílio Diniz. As licenciaturas e as novas políticas educacionais para a formação docente. Educação \& Sociedade, Campinas, v. 20, n. 68, p. 109-125, dez. 1999. 
PEREZ, Geraldo. Formação de professores de Matemática sob a perspectiva do desenvolvimento profissional. In: BICUDO, Maria Aparecida Viggiani. Pesquisa em Educação Matemática: concepções \& perspectivas. São Paulo: EdUNESP, 1999, p. 263282.

RIOS, Terezinha Azeredo. Compreender e ensinar: por uma docência da melhor qualidade. 8. ed. São Paulo: Cortez, 2010.

SANTOS, Mariana dos; TAVARES, Diego; FREITAS, Denise. A escolha da profissão professor: uma história envolvendo o passado. In: ENCONTRO NACIONAL DE PESQUISA EM EDUCAÇÃO EM CIÊNCIAS, 9, 2013, Águas de Lindóia. Anais do IX ENPEC. Águas de Lindóia: ABRAPEC, 2013, p. 1-8.

SOUZA, Jobeane França de. Identidade profissional no ensino superior: a escolha do magistério como profissão. In: COLÓQUIO INTERNACIONAL EDUCAÇÃO E CONTEMPORANEIDADE, 6, 2012, São Cristóvão. Anais do VI EDUCON. São Cristóvão: UFS, 2012, p. 1-12

STAMBERG, Cristiane da Silva; NEHRING, Cátia Maria. A escolha pela docência: influências do professor formador. In: SEMINÁRIO DE INICIAÇÃO CIENTÍFICA, 24, 2016, Ijuí. Anais do XXIV SIC. Ijuí: Unijuí, 2016, p. 1-6.

TARDIF, Maurice; LESSARD, Claude. O trabalho docente: elementos para uma teoria da docência como profissão de interações humanas. Tradução de João Batista Kreuch. 3. ed. Petrópolis: Vozes, 2005.

VIEIRA, Maria do Socorro Tavares Cavalcante. A escolha pela docência: decisão para a vida inteira. Revista Semiárido de Visu, Pernambuco, v. 4, n. 3, p. 123-131, jan. 2016. 